\title{
Leukocyte filtration to decrease the number of adherent leukocytes in the cerebral microcirculation after a period of deep hypothermic circulatory arrest
}

Hanna Alaoja, MS, a,b Eija Niemelä, MS, ${ }^{a, b}$ Vesa Anttila, MD, PhD, ${ }^{a, b}$ Sebastian Dahlbacka, MD, ,ab Jussi Mäkelä, MS, ${ }^{a, b}$ Kai Kiviluoma, MD, PhD, ${ }^{a, c}$ Päivi Laurila, MD, PhD, ${ }^{a, c}$ Timo Kaakinen, MD, PhD, a,b and Tatu Juvonen, MD, PhD ${ }^{a, b}$

Supplemental material is available online.
From the Clinical Research Center ${ }^{\mathrm{a}}$ and the Departments of Surgery ${ }^{\mathrm{b}}$ and Anesthesiology $^{\mathrm{c}}$ Oulu University Hospital and University of Oulu, Oulu, Finland.

Supported by grants from the Oulu University Hospital, the Finnish Foundation for Cardiovascular Research, and the Sigrid Juselius Foundation.

Received for publication June 5, 2006; revisions received July 31, 2006; accepted for publication Aug 10, 2006.

Address for reprints: Hanna Alaoja, MS, Medical student, Clinical Research Center, Oulu University Hospital, PO Box 5000, 90014 Oulu University, Oulu, Finland (E-mail: halaoja@student.oulu.fi).

J Thorac Cardiovasc Surg 2006;132:1339-47 $0022-5223 / \$ 32.00$

Copyright $\odot 2006$ by The American Association for Thoracic Surgery

doi:10.1016/j.jtcvs.2006.08.041
Objective: Cardiopulmonary bypass and hypothermic circulatory arrest induce a systemic inflammatory response, including a cascade of leukocyte and endothelial cell activity, during the postischemic reperfusion phase. Accumulation of leukocytes in the brain can lead to neurologic problems after cardiac surgery. The beneficial effects of a leukocyte-depleting filter have been documented, but because of contradictory results the underlying function of the filter remains unclear.

Methods: Twenty-two juvenile piglets (6 to 8 weeks) were randomly assigned to undergo cardiopulmonary bypass with or without a leukocyte-depleting filter 60 minutes before and 60 minutes after a 75-minute hypothermic circulatory arrest at $18^{\circ} \mathrm{C}$. The cerebral vessels were visualized with intravital microscopy through a cranial window placed over the parietal cortex. Rhodamine staining was used to observe adherent and rolling leukocytes in the cerebral postcapillary venules. The animals were electively killed 1 hour after weaning from cardiopulmonary bypass.

Results: There were no significant differences between the study groups regarding hemodynamic data. Numbers of adherent activated leukocytes were lower in the leukocyte filtration group, reaching borderline statistical significance when assessed throughout the experiment (between-groups $P=.069$ ) and actual statistical significance when assessed during the rewarming period (between-groups $P=.029$ ).

Conclusion: The leukocyte-depleting filter succeeded in reducing the number of adherent leukocytes during the reperfusion period in an experimental operation with deep hypothermic circulatory arrest. Such a filter thus could mitigate cerebral reperfusion injury after cardiac surgery.

$\mathrm{H}$ ypothermic circulatory arrest (HCA) is implemented in elaborate surgical operations of the aortic arch requiring a clean, bloodless operating field. HCA is associated with an increase of neurologic complications, however, as a result of global cerebral ischemia and reperfusion injury. Numerous studies have attempted to find means to improve the outcome of patients after surgery with HCA. ${ }^{1-3}$ The immunologic component of the reperfusion injury after deep HCA is thought to play a major role in the development of postoperative cerebral damage. Cardiopulmonary bypass (CPB) and HCA induce a systemic inflammatory response consisting of activation of the complement and coagulation systems and stimulation of cytokine production, as well as a cascade of leukocyte and endothelial cell activity.

In several studies, reduced accumulation of leukocytes has been associated with reduction in histologic inflammatory response ${ }^{4}$ and ischemic brain injury. ${ }^{5}$ The leukocyte-depleting filter has been thought to attenuate postoperative, postischemic organ dysfunction in the myocardium of the heart ${ }^{6}$ and in the lungs. ${ }^{7}$ In our previous study leukocyte filtration during CPB mitigated cerebral damage after HCA. ${ }^{8}$ The 


\section{Abbreviations and Acronyms \\ $\mathrm{CPB}=$ cardiopulmonary bypass \\ $\mathrm{HCA}=$ hypothermic circulatory arrest}

exact effect of a leukocyte-depleting filter in cerebral vessels, however, has not been verified. There has been abundant discussion about whether the filter improves the outcome purely by reducing the number of activated leukocytes in cerebral circulation or by acting as a filter in general, filtrating out such other harmful products as microemboli as well. ${ }^{9}$ Studies on this matter have been contradictory. For example, Chen and colleagues ${ }^{10}$ found that the leukocytedepleting filter downregulated the expression of CD11b ( $\beta_{2}$-integrin) and L-selectin, whereas Ilmakunnas and coauthors ${ }^{11}$ demonstrated that the use of leukocyte-depleting filter could actually lead to higher CD11b expression and neutrophil hydrogen peroxidase production.

In this study, we aimed to illustrate the effects of leukocyte filtration in cerebral microcirculation through direct visualization with intravital microscopy, which allowed us to perform real-time observation of superficial cerebral vessels. Our aim was to investigate whether leukocyte filtration affects endothelial cell and leukocyte adhesion in the brain in an operation requiring the use of deep HCA.

\section{Methods}

\section{Experimental Setting}

Twenty-two juvenile (6-7 weeks) piglets from a native stock were randomly assigned to undergo CPB with or without a leukocytedepleting filter (LeukoGuard LG6; Pall Biomedical, Portsmouth, UK) 60 minutes before and 60 minutes after a 75 -minute HCA at $18^{\circ} \mathrm{C}$.

\section{Preoperative Management}

All animals received humane care in accordance with the "Principles of Laboratory Animal Care" formulated by the National Society for Medical Research and the "Guide for the Care and Use of Laboratory Animals" (http://www.nap.edu/catalog/5140.html). The study was approved by the Research Animal Care and Use Committee of the University of Oulu.

\section{Anesthesia Protocol}

Piglets were sedated with intramuscular ketamine hydrochloride $(350 \mathrm{mg})$ and midazolam $(45 \mathrm{mg})$, and a peripheral catheter was inserted into a vein of the right ear for administration of drugs and to maintain fluid balance with Ringer acetate solution. With thiopental used for further sedation as required, the piglets were intubated with a 6-mm cuffed endotracheal tube and ventilated with $50 \%$ oxygen at a rate of 12 to 15 breaths/min to achieve an end-tidal carbon dioxide concentration in the expired air of $4.5 \%$ to $5.0 \%$. After induction with fentanyl $(50 \mu \mathrm{g} / \mathrm{kg})$, anesthesia was maintained by a continuous infusion of fentanyl $(25 \mu \mathrm{g} /[\mathrm{kg} \cdot \mathrm{h}])$, midazolam $(0.25 \mathrm{mg} /[\mathrm{kg} \cdot \mathrm{h}])$, and pancuronium $(0.2 \mathrm{mg} /[\mathrm{kg} \cdot \mathrm{h}])$, as well as inhalation anesthesia of $0.5 \%$ isoflurane throughout the entire experiment, excluding HCA. Cefuroxime at $1.5 \mathrm{~g}$ was administered intravenously at anesthesia induction. Electrocardiographic monitoring was carried out throughout the entire operation.

\section{Hemodynamic Monitoring}

An arterial line for arterial pressure monitoring and blood sampling was placed on the left femoral artery. A pulmonary artery thermodilution catheter (CritiCath 7F; Ohmeda $\mathrm{GmbH} \& \mathrm{Co}$, Erlangen, Germany) was introduced through the left femoral vein for blood sampling, monitoring the pulmonary pressure, measuring the cardiac output, pulmonary capillary wedge pressure, and central venous pressure, and recording of the temperature of blood. A $10 \mathrm{~F}$ catheter was placed in the urinary bladder to monitor urine output. The right femoral artery was also exposed for a CPB arterial cannula.

A right anterolateral thoracotomy was performed in the fourth intercostal space to expose the right atrium for venous cannulation. The right thoracic vessels were ligated and cut, and the pericardium was opened. After systemic heparinization (500 IU/kg), a $12 \mathrm{~F}$ arterial cannula and a $24 \mathrm{~F}$ atrial cannula were inserted into the right femoral artery and the right atrial appendage, respectively.

\section{Cranial Procedures}

After cannulation, the piglets were positioned prone and secured. A cranial window $(15 \times 15 \mathrm{~mm})$ was created over the right parietal cerebral cortex with an electric drill. After incision of the dura, the surface (pial) vessels were visualized. An additional, smaller hole was drilled through the posterior part of the left parietal cortex for a probe to monitor intracerebral temperature (Thermocouple Temperature Catheter-Micro-Probe, Ref C8.B; GMS mbH, Mielkendorf, Germany) throughout the experiment. The baseline intravital microscopy recording was performed, and the baseline parameters were recorded.

\section{Cardiopulmonary Bypass}

After baseline recordings, a membrane oxygenator (D905 Eos; Dideco SpA, Mirandola, Italy) was primed with $1 \mathrm{~L}$ Ringer acetate and heparin (5000 IU). All blood in the circuit during the experiment was from the animal itself; no blood transfusions were made, and no blood was used to prime the CPB circuit. The leukocytedepleting filter was placed on the arterial line of the CPB circuit. There was no separate arterial line filter. Nonpulsatile CPB was initiated at a flow rate of 90 to $110 \mathrm{~mL} /(\mathrm{kg} \cdot \mathrm{min})$, and the flow was adjusted to maintain an arterial pressure of 50 to $70 \mathrm{~mm} \mathrm{Hg}$. A 12F intracardiac sump cannula was positioned into the left ventricle through the apex of the heart for decompression of the left side of the heart during CPB. After 10 minutes of normothermic perfusion at $37^{\circ} \mathrm{C}$, a 60 -minute cooling period was carried out to attain a brain temperature of $18^{\circ} \mathrm{C}$. A heat exchanger was used for core cooling.

After 60 minutes of cooling, a 75-minute period of HCA at $18^{\circ} \mathrm{C}$ was initiated, and potassium chloride $(40 \mathrm{mmol})$ was injected toward the heart through the CPB arterial cannula. Cardiac cooling with topical ice slush was maintained throughout HCA. The intracerebral temperatures were controlled and maintained at $18^{\circ} \mathrm{C}$ with ice packs placed over the head. 
At the beginning of rewarming, furosemide $(40 \mathrm{mg})$, mannitol (150 g), and lidocaine (40 mg) were administered into the pump. During 60 minutes of rewarming, the piglets were warmed to $37^{\circ} \mathrm{C}$ with a $100 \mathrm{~mL} /(\mathrm{kg} \cdot \mathrm{min})$ flow rate. The heart was defibrillated if necessary at $30^{\circ} \mathrm{C}$. The left ventricular sump cannula was removed after 45 minutes of rewarming. Ventilation ( $50 \%$ oxygen) was started 10 minutes before weaning from $\mathrm{CPB}$, which itself occurred at 60 minutes after the start of rewarming.

The piglets remained sedated and paralyzed and were mechanically ventilated for 60 minutes after weaning from CPB (2 hours after HCA). After this, piglets were humanely killed with intravenous pentobarbital $(60 \mathrm{mg} / \mathrm{kg})$.

\section{Intravital Microscopy}

An intravital microscope (Leica Model MZFL III; Leica, Heerbrugg, Switzerland) was placed over the cranial window and mounted on a surgical stand to stabilize the view. The microscope included two sets of filters: a violet filter (450-490 nm excitation, $>515 \mathrm{~nm}$ emission wavelength) to visualize microvascular perfusion and a green filter (536-556 nm excitation, >590 nm emission wavelength) for visualization of rhodamine-labeled leukocytes.

The image was captured by the charge-coupled device video camera (CCD 300-ETRCX; Dage-MTI, Michigan City, Ind), transferred to a monitor (LCD SyncMaster 710mp; Samsung Electronics Co, Ltd, Seoul, South Korea), and videotaped. A frame grabber (Kudo Interactive Frame Grabber; Kudo Interactive, Westminster, Colo) and a computer-assisted image analysis system (Scion Corporation, Frederick, Md) were used for offline analysis. The final magnification on the monitor was 400 times. At baseline the piglet received a $2-\mathrm{mL}(4 \mathrm{mg} / \mathrm{mL})$ loading dose of rhodamine 6G chloride MW 479 (Sigma Chemical Co, St Louis, Mo) 5 minutes before the initial recording.

Violet filter. When a suitable field of vision was discovered, a $1-\mathrm{mL}(50 \mathrm{mg} / \mathrm{mL})$ intravenous bolus of fluorescein isothiocyanatelabeled dextran (150 kd; Fluka Chemicals, St Louis, Mo) was administered to label the plasma of the cerebral vessels, and a recording was made with the violet filter of the microscope. The plasma became highlighted, and the red blood cells appeared dark. The diameter of 20 to $50 \mu \mathrm{m}$ arterial and venous cerebrocortical microvessels was measured from video still images by using an image analysis program. In each animal, three arterioles and three venules were selected from the observation area. Each measurement was referred to baseline, so that the baseline diameter of the vessel was $100 \%$.

Green filter. The piglet received a $1-\mathrm{mL}(4 \mathrm{mg} / \mathrm{mL})$ intravenous bolus of rhodamine to stain the activated leukocytes in the circulation. A recording was made with the green filter. From each animal, a postcapillary venule was selected to represent the quantities of adherent and rolling leukocytes. The exact number of adherent leukocytes was calculated from an easily determined portion of the vessel, and the number of cells was then related to the surface area rendered. The analysis was made by an investigator unaware of the protocol by using both still pictures and videotapes. For rolling leukocytes, a specific point of the vessel was selected, and the number of leukocytes rolling past that point was observed during approximately 10 to 15 seconds in each recording.
Similar recordings were made at 11 time points: at baseline; at 10 minutes of normothermic CPB; at 30 and 60 minutes of cooling; at 5, 15, 30, 45, and 60 minutes of rewarming; and finally at 90 and 120 minutes after HCA. The epi-illumination was limited to less than 1 minute to avoid thermal injury, and the epi-illumination was always stopped between video recordings.

\section{Biochemical Data}

Blood gas values, $\mathrm{pH}$, electrolytes, complete blood cell counts, serum ionized calcium, glucose and hemoglobin levels (i-STAT Analyzer; i-STAT Corporation, East Windsor, NJ) were measured at baseline, at the end of cooling (immediately before institution of HCA), and at 30 minutes, 1 hour, and 2 hours after the start of rewarming. To control $\mathrm{PaCO}_{2}$ precisely, sampling was performed at least every 15 minutes during $\mathrm{CPB}$.

\section{Statistical Analysis}

Statistical analysis was performed with SPSS (version 12.0; SPSS Inc, Chicago, Ill) and SAS (version 9.1.3; SAS Institute, Inc, Cary, NC) statistical software packages. Continuous and ordinal variables are expressed as the median and 25th and 75th percentiles (interquartile range). The SAS procedure Mixed was used for repeated measurements. Because the measurement intervals were uneven, spatial exponential covariance structure was defined in repeated statement. Complete independence was assumed across animals (by random statement). Reported $P$ values are as follows: $P$ between groups $\left(P_{\mathrm{g}}\right)$ indicates a level of difference between the groups, $P$ for time by group $\left(P_{\mathrm{t}^{* \mathrm{~g}}}\right)$, indicates behavior between the groups with time. Either the Student $t$-test or Mann-Whitney $U$ test was used to assess the distribution of variables between the study groups. Two-tailed significance levels are reported.

\section{Results \\ Comparison of Study Groups}

The weights of the pigs were $23.6 \mathrm{~kg}(21.3-26.1 \mathrm{~kg})$ in the leukocyte filtration group and $21.8 \mathrm{~kg}(20.5-23.1 \mathrm{~kg})$ in the control group $(P=.08)$. Twenty-seven pigs underwent the operation. Three pigs had severe brain hemorrhage resulting from drilling of the skull and manipulation of the dura. In 2 animals, the area of illumination failed to achieve reperfusion after HCA. All 5 of these animals were excluded from analysis. Thus each group contained 11 animals. Experimental and metabolic data are shown in Table I.

\section{Temperatures}

The median cooling and rewarming times did not differ between the study groups and lasted for a median of 60 minutes. The preoperative body temperature of the leukocyte filtration group was slightly lower than that of the control group; after 10 minutes of normothermic perfusion, however, this difference was rectified (Table 1). There were no significant differences between the groups regarding temperatures during the rest of the experiment. After the normothermic animals were weaned from the CPB at 60 minutes of rewarming, the temperatures in both groups 
TABLE 1. Experimental and metabolic data

\begin{tabular}{|c|c|c|c|c|c|c|c|c|}
\hline & & & & & start of rew & ing & & \\
\hline & Baseline & $20 \mathrm{~min}$ & End & $30 \mathrm{~min}$ & $1 \mathrm{~h}$ & $2 \mathrm{~h}$ & $P_{\mathrm{g}}$ & $\boldsymbol{P}_{\mathrm{t} * \mathrm{~g}}$ \\
\hline $\mathrm{pH}$ & & & & & & & .01 & .28 \\
\hline Leukocyte filter & & & & & & & & \\
\hline Median & 7.50 & $7.45^{*}$ & 7.46 & $7.31^{*}$ & 7.33 & 7.20 & & \\
\hline Interquartile range & $7.43-7.55$ & 7.38-7.47 & $7.43-7.50$ & 7.28-7.34 & $7.28-7.36^{*}$ & $7.15-7.23$ & & \\
\hline Control & & & & & & & & \\
\hline Median & 7.49 & 7.41 & 7.45 & 7.28 & 7.27 & 7.14 & & \\
\hline Interquartile range & $7.45-7.52$ & 7.37-7.42 & 7.36-7.48 & 7.24-7.31 & 7.23-7.33 & 7.09-7.23 & & \\
\hline $\mathrm{PaCO}_{2}(\mathrm{kPa})$ & & & & & & & .89 & .01 \\
\hline Leukocyte filter & & & & & & & & \\
\hline Median & 5.72 & 5.24 & $4.93^{*}$ & 5.14 & 5.10 & $6.55^{*}$ & & \\
\hline Interquartile range & $5.18-6.00$ & $5.11-5.47$ & $4.75-5.13$ & $4.61-5.63$ & $4.79-5.43$ & $6.24-7.30$ & & \\
\hline Control & & & & & & & & \\
\hline Median & 5.36 & 5.63 & 5.09 & 5.20 & 5.09 & 6.18 & & \\
\hline Interquartile range & $4.78-5.89$ & $5.19-6.00$ & $4.96-5.53$ & $4.76-5.56$ & $4.69-5.62$ & $5.80-6.37$ & & \\
\hline $\mathrm{PaO}_{2}(\mathrm{kPa})$ & & & & & & & .08 & .84 \\
\hline Leukocyte filter & & & & & & & & \\
\hline Median & 36.3 & 106.0 & 106.0 & 74.9 & 72.6 & 32.1 & & \\
\hline Interquartile range & $34.3-36.7$ & $106.0-106.0$ & $106.0-106.0$ & $69.7-79.2$ & $66.5-76.2$ & $19.9-34.3$ & & \\
\hline Control & & & & & & & & \\
\hline Median & 34.4 & 106.0 & 106.0 & 73.3 & 70.0 & 23.9 & & \\
\hline Interquartile range & $29.6-38.0$ & $106.0-106.0$ & $106.0-106.0$ & $65.5-79.6$ & $60.4-77.8$ & $14.0-30.4$ & & \\
\hline Mixed venous oxygen sa & ration $(\%)$ & & & & & & .21 & .22 \\
\hline Leukocyte filter & & & & & & & & \\
\hline Median & 78.0 & 77.2 & 95.8 & 47.0 & 38.9 & 49.5 & & \\
\hline Interquartile range & $70.0-80.0$ & 75.7-87.4 & $95.0-96.3$ & $42.1-53.1^{*}$ & $27.9-45.5$ & $38.3-62.0$ & & \\
\hline Control & & & & & & & & \\
\hline Median & 75.0 & 87.5 & 96.0 & 56.5 & 45.0 & 50.0 & & \\
\hline Interquartile range & $66.0-83.0$ & $82.3-89.5$ & $95.8-96.3$ & $54.8-58.8$ & 43.3-49.5 & $32.0-55.5$ & & \\
\hline Mean arterial pressure ( & $\mathrm{n} \mathrm{Hg)}$ & & & & & & .63 & .003 \\
\hline Leukocyte filter & & & & & & & & \\
\hline Median & 86 & 59 & 61 & 55 & 57 & 57 & & \\
\hline Interquartile range & $68-99$ & $54-62$ & $55-63$ & $48-57$ & $50-59$ & $48-59$ & & \\
\hline Control & & & & & & & & \\
\hline Median & 97 & 56 & 62 & 51 & 53 & 52 & & \\
\hline Interquartile range & 83-108 & $53-60$ & $56-63$ & $47-56$ & $49-55$ & $46-57$ & & \\
\hline Cardiac indext (cardiac & tput or pump & $\left.\mathrm{ow} /\left[\mathrm{min} \cdot \mathrm{m}^{2}\right]\right)$ & & & & & .15 & .18 \\
\hline Leukocyte filter & & & & & & & & \\
\hline Median & 3.07 & 2.86 & 2.79 & 3.11 & 2.93 & 2.97 & & \\
\hline Interquartile range & $2.68-3.90$ & 2.67-3.07 & $2.36-2.90$ & 2.61-3.32 & $2.66-3.11$ & $2.47-3.50$ & & \\
\hline Control & & & & & & & & \\
\hline Median & $3.81^{*}$ & 3.02 & 2.58 & 3.25 & 3.29 & 3.05 & & \\
\hline Interquartile range & $3.16-4.46$ & $2.44-3.25$ & $2.33-3.12$ & $2.76-3.49$ & $2.68-3.50$ & $2.18-3.67$ & & \\
\hline Pulmonary artery pressu & (mm Hg, sys & ic/diastolic) & & & & & $.32 / .18$ & $.77 / .74$ \\
\hline Leukocyte filter & & & & & & & & \\
\hline Median & $18 / 11$ & - & - & - & - & $34 / 24$ & & \\
\hline Interquartile range & $16 / 10-22 / 16$ & - & - & - & - & $28 / 17-38 / 29$ & & \\
\hline Control & & & & & & & & \\
\hline Median & $23 / 14$ & - & - & - & - & $35 / 23$ & & \\
\hline Interquartile range & 19/11-24/16 & - & - & - & - & $26 / 15-37 / 29$ & & \\
\hline
\end{tabular}


TABLE 1. Continued

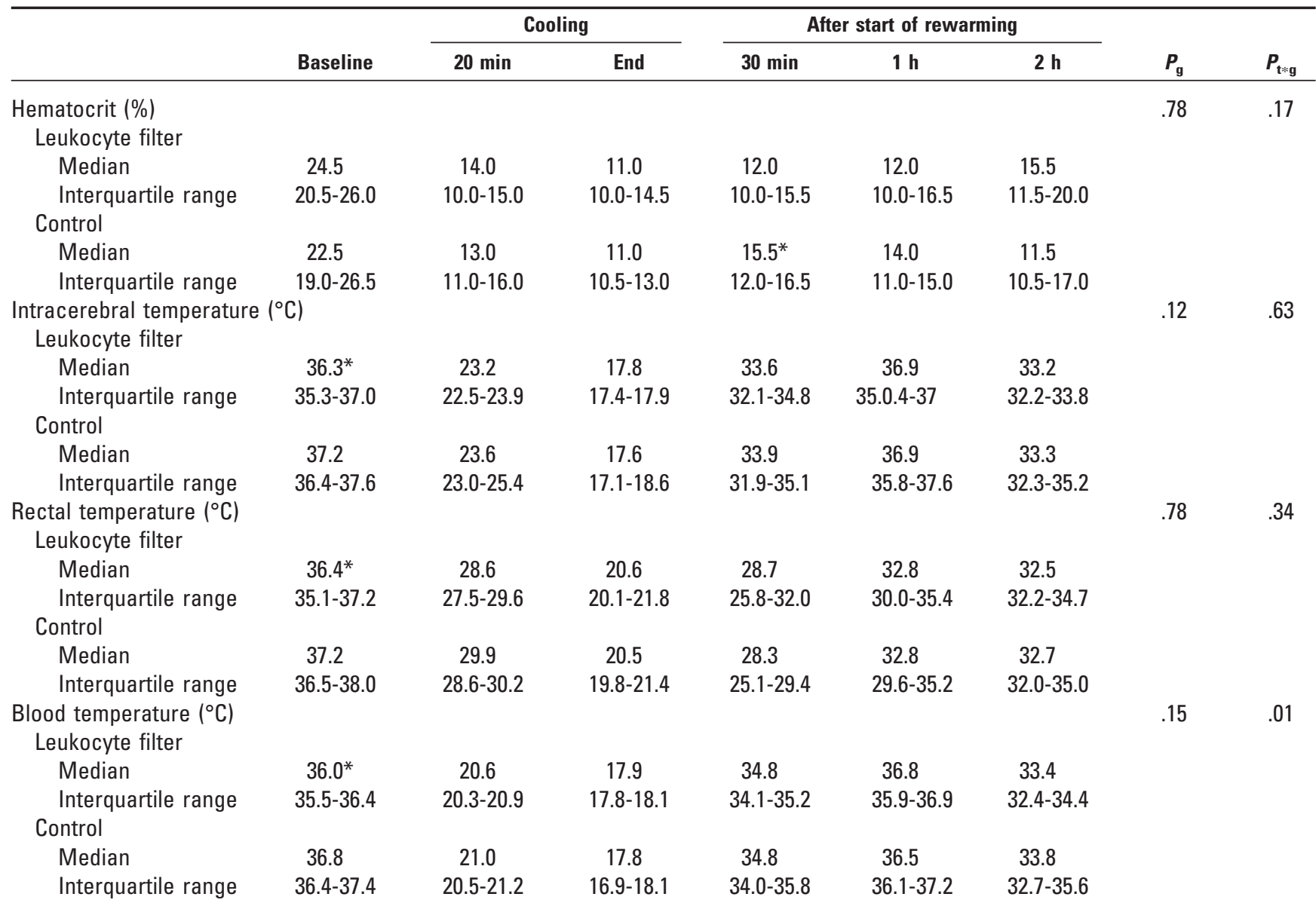

Interquartile range represents the range between the 25th and 75th percentiles; $P_{\mathrm{g}}$ represents the level of difference between groups; $P_{\mathrm{t} * \mathrm{~g}}$ represents the behavior between groups with time. $* P<.05$ at single time point. $\uparrow$ At baseline and 2 hours after hypothermic circulatory arrest, cardiac output was used in determining cardiac index. At other time points, determining value was pump flow.

began to decline again, so that at the end of the experiment all animals were slightly hypothermic.

\section{Hemodynamic Data}

There were no significant differences between the groups concerning heart rate $\left(P_{\mathrm{g}}=.70\right)$, central venous pressure $\left(P_{\mathrm{g}}=.77\right)$, pump flow $\left(P_{\mathrm{g}}=.78\right)$, vascular resistance $\left(P_{\mathrm{g}}>\right.$ .9), and $\mathrm{PaO}_{2}\left(P_{\mathrm{g}}=.08\right)$ during the entire experiment. There was less alteration in mean arterial pressure in the leukocyte filtration group. At baseline the cardiac index was slightly better in the control group, but no further significant differences were observed.

Both groups were sufficiently ventilated and oxygenated, without any clinically relevant differences between groups. Hematocrit remained under baseline values as a result of hemodilution throughout the experiment in both groups, but it tended to be higher in the control group during rewarming, reaching a statistically significant difference at $30 \mathrm{~min}-$ utes after HCA. Similarly, venous saturation of oxygen tended to be higher in the control group during $\mathrm{CPB}$, with the difference reaching statistical significance at 30 minutes of rewarming. It is worth noting the exceptionally high pulmonary artery pressures in both groups at the end of the experiment relative to baseline (Table 1).

\section{Metabolic Data}

There were no significant differences between the groups concerning oxygen delivery $\left(P_{\mathrm{g}}=.37\right)$, oxygen consumption $\left(P_{\mathrm{g}}=.72\right)$, oxygen extraction $\left(P_{\mathrm{g}}=.46\right)$, venous blood glucose $\left(P_{\mathrm{g}}=.33\right)$, or ionized calcium $\left(P_{\mathrm{g}}=.23\right)$ at any point of the experiment.

\section{Systemic Blood Cell Count}

The systemic white blood cell count and the neutrophil count remained fairly similar between groups until the end point of the experiment (Table 2). Two hours after HCA, the white blood cell count and the neutrophil count were significantly higher in the leukocyte filtration group. There 
TABLE 2. Complete blood cell count

\begin{tabular}{|c|c|c|c|c|c|c|c|}
\hline & \multirow[b]{2}{*}{ Baseline } & \multirow[b]{2}{*}{ End cooling } & \multicolumn{3}{|c|}{ After start of rewarming } & \multirow[b]{2}{*}{$P_{\mathrm{g}}$} & \multirow[b]{2}{*}{$\boldsymbol{P}_{t * g}$} \\
\hline & & & $30 \mathrm{~min}$ & $1 \mathrm{~h}$ & $2 \mathrm{~h}$ & & \\
\hline \multicolumn{6}{|c|}{ White blood cell count $\left(10^{9}\right.$ cells/L) } & .28 & .032 \\
\hline \multicolumn{8}{|l|}{ Leukocyte filter } \\
\hline Median & 20.0 & 3.3 & 5.3 & 5.2 & $8.8^{*}$ & & \\
\hline Interquartile range & $17.5-24.5$ & $1.6-4.5$ & $3.0-7.2$ & $4.2-8.1$ & $6.6-15.7$ & & \\
\hline \multicolumn{8}{|l|}{ Control } \\
\hline Median & 22.5 & 2.9 & 4.8 & 4.2 & 4.2 & & \\
\hline Interquartile range & 15.4-24.1 & $2.3-5.1$ & $1.9-6.3$ & $3.2-5.0$ & $2.1-8.3$ & & \\
\hline \multicolumn{6}{|c|}{ Neutrophil count $\left(10^{9}\right.$ cells/L) } & .17 & .024 \\
\hline \multicolumn{8}{|c|}{ Leukocyte filter } \\
\hline Median & 8.9 & 1.2 & 1.3 & 1.3 & $3.4^{*}$ & & \\
\hline Interquartile range & $8.5-12.3$ & $0.7-1.6$ & $0.8-3.1$ & $1.0-3.4$ & $1.5-9.2$ & & \\
\hline \multicolumn{8}{|l|}{ Control } \\
\hline Median & 10.2 & 1.4 & 1.2 & 0.8 & 0.5 & & \\
\hline Interquartile range & $7.9-12.1$ & $0.5-2.2$ & $0.7-1.7$ & $0.5-1.5$ & $0.3-1.0$ & & \\
\hline \multicolumn{3}{|c|}{ Lymphocyte count $\left(10^{9}\right.$ cells/L) } & & & & $>.9$ & .14 \\
\hline \multicolumn{6}{|l|}{ Leukocyte filter } & & \\
\hline Median & 9.5 & 1.6 & 3.0 & 2.9 & 4.6 & & \\
\hline Interquartile range & $8.5-10.1$ & $1.2-2.4$ & 2.1-4.4 & 2.4-4.5 & $4.1-5.3$ & & \\
\hline \multicolumn{8}{|l|}{ Control } \\
\hline Median & 10.7 & 1.8 & 2.9 & 3.0 & 2.7 & & \\
\hline Interquartile range & $8.2-12.2$ & $1.1-3.5$ & $1.1-4.4$ & $1.8-3.6$ & $1.5-5.4$ & & \\
\hline \multicolumn{3}{|c|}{ Red blood cells $\left(10^{12}\right.$ cells/L) } & & & & .29 & .35 \\
\hline \multicolumn{6}{|l|}{ Leukocyte filter } & & \\
\hline Median & 5.6 & 3.3 & 3.4 & 3.4 & 4.4 & & \\
\hline Interquartile range & $4.9-6.4$ & $2.5-3.8$ & $2.8-3.8$ & $2.8-4.1$ & $3.3-5.3$ & & \\
\hline \multicolumn{6}{|l|}{ Control } & & \\
\hline Median & 5.5 & 3.2 & 3.5 & 3.4 & 3.4 & & \\
\hline Interquartile range & $5.0-5.8$ & 2.6-3.5 & $3.1-3.7$ & $3.0-3.7$ & $3.3-4.5$ & & \\
\hline \multicolumn{3}{|l|}{ Platelets $\left(10^{9}\right.$ cells/L) } & & & & .72 & .83 \\
\hline \multicolumn{6}{|l|}{ Leukocyte filter } & & \\
\hline Median & 330 & 80 & 166 & 177 & 210 & & \\
\hline Interquartile range & $293-478$ & $47-97$ & $121-202$ & $156-215$ & $152-248$ & & \\
\hline \multicolumn{6}{|l|}{ Control } & & \\
\hline Median & 347 & 80 & 205 & 219 & 219 & & \\
\hline Interquartile range & $232-556$ & $69-154$ & $184-230$ & $195-239$ & $191-266$ & & \\
\hline
\end{tabular}

Interquartile range represents the range between the 25th and 75th percentiles; $P_{\mathrm{g}}$ represents the level of difference between groups; $P_{\mathrm{t} * \mathrm{~g}}$ represents the behavior between groups with time. $* P<.05$ at single time point.

were no significant differences between the groups concerning lymphocytes, red blood cells, and platelets.

\section{Intravital Microscopy}

Vessel diameter. The baseline diameters of selected arteries were $31.7 \mu \mathrm{m}(26.1-35.9 \mu \mathrm{m})$ in the leukocyte filtration group and $34.1 \mu \mathrm{m}(27.6-42.0 \mu \mathrm{m})$ in the control group $(P=.20)$. As for the veins, at baseline the diameters were $40.1 \mu \mathrm{m}(31.6-48.5 \mu \mathrm{m})$ in the leukocyte filtration group and $41.3 \mu \mathrm{m}(37.1-47.8 \mu \mathrm{m})$ in the control group $(P=.43)$. There were no significant differences between the groups concerning the behavior of the arteries throughout the experiment $\left(P_{\mathrm{g}}=.54\right)$. Most of the arteries in both groups reacted as expected: they dilated during the normothermic $\mathrm{CPB}$, constricted during cooling, reached their baseline diameters during rewarming, then slightly constricted as the animal was weaned from CPB. In the veins, no specific pattern of behavior was observed; veins seemed to dilate as $\mathrm{CPB}$ was initiated and to remain so until the end of the experiment $\left(P_{\mathrm{g}}=.71\right)$.

Adherent leukocytes. The baseline diameters of the selected veins were $29.2 \mu \mathrm{m}(25.9-33.6 \mu \mathrm{m})$ in the leukocyte filtration group and $29.6 \mu \mathrm{m}(24.0-35.3 \mu \mathrm{m})$ in the control group $(P=.47)$. The lengths of vessel portions were 104.6 $\mu \mathrm{m}(103.2-107.4 \mu \mathrm{m})$ in the leukocyte filtration group and $100.6 \mu \mathrm{m}(91.4-106.9 \mu \mathrm{m})$ in the control group $(P=.20)$. 


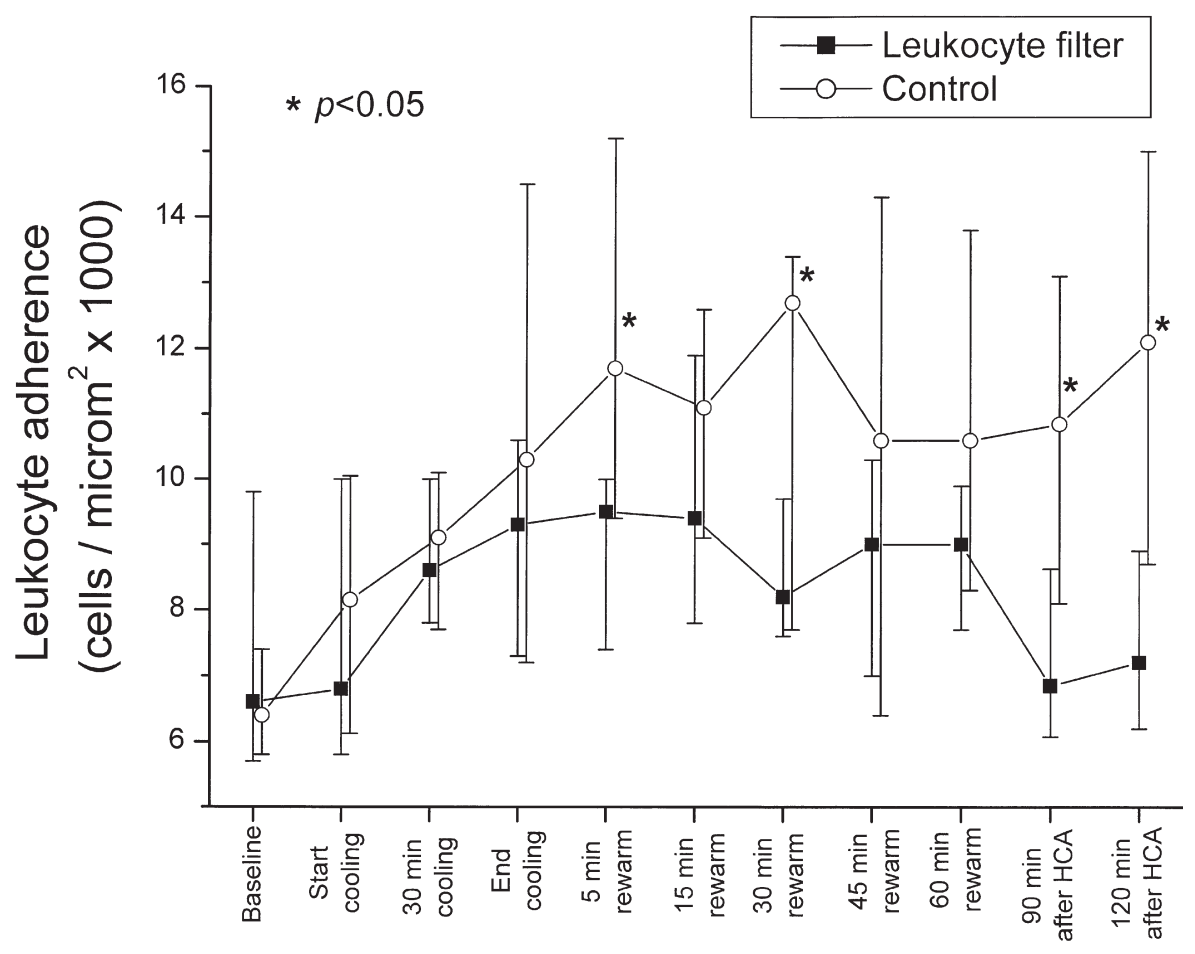

Figure 1. Adherent leukocytes. Values are shown as medians and 25th and 75th percentiles. Leukocyte filtrationgroup had fewer adherent leukocytes after hypothermic circulatory arrest (HCA, $\left.P_{\mathrm{g}}=.029\right)$.

The number of adherent leukocytes appeared to be lower in the leukocyte filtration group (Figure 1). This trend started to appear at the end of cooling, and the difference was statistically significant at four time points $(5$ minutes of rewarming $P=.02,30$ minutes of rewarming $P=.048,90$ minutes of rewarming $P=.026$, an 120 minutes of rewarming $P=.025)$. The difference just missed the $5 \%$ significance level $\left(P_{\mathrm{g}}=.067\right)$. When we assessed only the period after $\mathrm{HCA}$, the rewarming period and after weaning from the CPB, however, there was a statistically significant level of difference between the groups $\left(P_{\mathrm{g}}=.029\right)$. Examples of still images obtained by the intravital microscope can be seen in Figure E1.

The behavior of the groups was significantly different for both the entire experiment $\left(P_{\mathrm{t}^{* \mathrm{~g}}}=.001\right)$ and only the time period after HCA $\left(P_{\mathrm{t}^{*} \mathrm{~g}}=.001\right)$. In general, the leukocyte filtration group demonstrated the highest number of adherent leukocytes immediately 5 minutes after the start of rewarming, whereas the number of adherent leukocytes in the control group kept climbing during the rewarming period, reaching its peak at 30 minutes after the start of rewarming. At the end of the experiment, the control group showed elevated numbers of adherent leukocytes, whereas in the leukocyte filtration group the adherence was closer to baseline levels.

Rolling leukocytes. The same vein used to calculate leukocyte adherence was also used in observing the rolling leukocytes. There were no significant differences between the groups (Figure 2). In both groups, larger numbers of rolling leukocytes were observed as rewarming was commenced. Toward the end of the experiment, the number of rollers was reduced, so that at 2 hours after HCA there were fewer rollers than at the baseline measurement.

\section{Discussion}

Leukocytes have interested researchers for decades, because they have been thought to aggravate postischemic reperfusion injury in several ways. As they are activated, most probably by a combination of ischemia, inflammatory signals from the damaged area, contact with foreign surfaces of the extracorporeal circulation, and mechanical shear forces, they start to form temporary bonds with the vessel wall endothelium. This transient bonding is mediated by selectin, and it leads to "rolling" leukocytes moving along the vessel wall at a reduced speed, intermittently tethering to the endothelium. ${ }^{12}$ Stronger bonds between the cells and the endothelium are brought about by leukocyte $\beta$ integrins (CD11/CD18) binding to intercellular adhesion molecules 1 and possibly $2 .{ }^{13}$ Finally, assisted by interleukin- 8 and platelet-endothelial cell adhesion molecule 1, the leukocytes are thought to migrate through the vessel wall into surrounding tissue. ${ }^{14,15}$ As this activation process commences, leukocyte adherence to the capillary walls leads to obstructed blood flow in the cerebral capillary bed, causing secondary ischemia. Further, leukocyte infiltration into surrounding tissues is accompanied by disruption of the blood- 


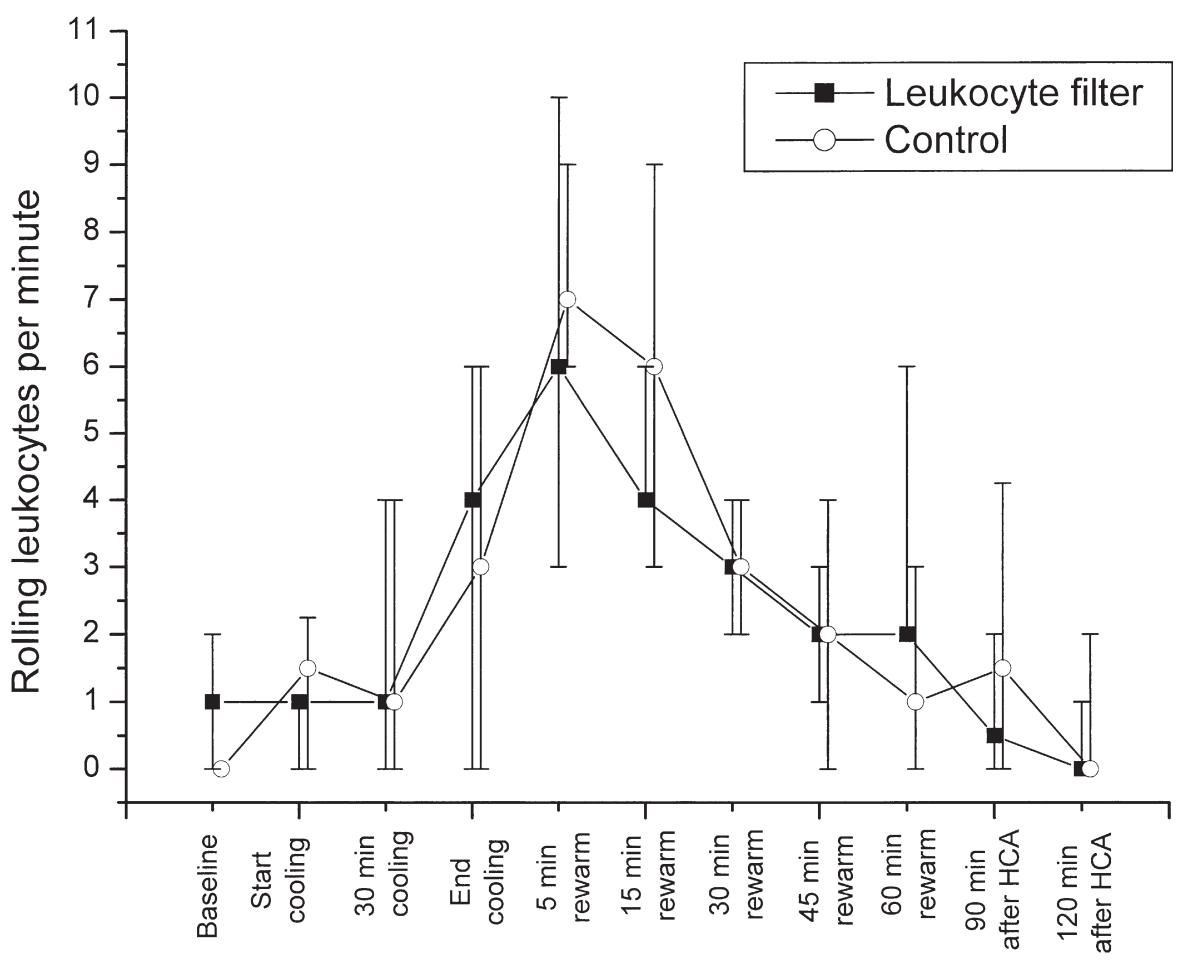

brain barrier, mediated in part by enzymes released from activated leukocytes. ${ }^{16}$ The accumulation of leukocytes in tissues causes tissue damage and cerebral edema, which can lead to an increased intracranial pressure. Furthermore, the damaged endothelium of cerebral vessels secretes powerful vasoconstrictors, such as endothelin and thromboxane $A_{2}$, leading to abnormal decrease of diameter in cerebral circulation. $^{17}$

This study demonstrates that the leukocyte-depleting filter reduces the number of adherent leukocytes in the cerebral vessels of a piglet after a period of deep HCA. This result can be observed directly from intravital microscopy data. The result failed to reach strict statistical significance in a continuous analysis of repeated measurements concerning the whole experiment, possibly because of our small sample size. Of utmost importance is the period after HCA, however, because that is the time when the so-called reperfusion injury, including the harmful leukocyte activation, takes place. During that period, from the start of rewarming to 2 postoperative hours, the leukocyte filtration group demonstrated significantly lower amounts of adherent leukocytes.

The difference observed in adherent leukocytes was not displayed in the statistics of the rolling leukocytes. One possible reason could be the time limit imposed on each recording; because illuminations were frequent and multiple, exposure of brain tissue had to be as short as possible (about 10 to 15 seconds to observe the rolling leukocytes),
Figure 2. Rolling leukocytes. Values are shown as medians and 25th and 75th percentiles. There were no differences between groups. HCA, Hypothermic circulatory arrest. and very few actual rollers were caught by the video. Maybe to witness any real difference between the groups, the observation time should have been longer. Because these two stages, rolling and adhering, are so closely connected, however, it is reasonable to assume that had our method been sufficient we might have been able to see a downward trend in the rolling leukocytes of the leukocyte filtration group as well.

The difference in adherent leukocytes coexisted with the finding that in systemic blood flow there were mostly no differences between the groups concerning white blood cell count and neutrophil count. In fact, at the end of the experiment these measurements were even higher in the leukocyte filtration group. This observation supports the assumption that the LG-6 filter selectively removes activated neutrophils but does not have a significant enough effect to reduce the total leukocyte or total neutrophil count. ${ }^{18}$ It also implies that systemic evaluation of white blood cell count and neutrophil count may not reveal the whole truth about the numbers of activated leukocytes locally in the brain. Our findings are limited to the number of leukocytes in the cerebral venules, however; their function and reactivity are not assessed here. It has been speculated that leukocytes caught in the mesh of the filter can still secrete harmful substances. ${ }^{19}$

Hypothermic CPB in itself has been documented to reduce inflammatory response to $\mathrm{CPB}$ and ischemic injury relative to normothermic $\mathrm{CPB}$. There were no differences 
between the groups concerning temperature and flow rate during the experiment, an important finding because these are stated to be independent predictors of the numbers of rolling and adherent leukocytes. ${ }^{20}$

The lack of differences between groups concerning the behavior of arteries and veins was to be expected. To demonstrate any real changes in the cerebral circulation related to the decreased number of leukocytes, one should investigate larger vessels (perhaps arterioles around $100 \mu \mathrm{m}$ in diameter, because they are considered to be in charge of autoregulatory function in the brain) deeper in the brain tissue. The capillaries we observed were naturally on the surface of the brain and were perhaps too small to reflect relevant changes in the circulation of the whole tissue.

All animals were slightly acidic toward the end of the experiment, and the minor differences between the groups concerning $\mathrm{pH}$, hematocrit, and oxygen saturation were not significant to our study in a clinical sense. After weaning from $\mathrm{CPB}$, the pulmonary arterial pressure tended to remain abnormally high in both groups. We suspect that the exceptional load on the right side of the heart from accumulation of rhodamine in the bloodstream and tissues was one factor that led to poorer cardiovascular status toward the end of the experiment.

We conclude that in this experimental setting the leukocyte-depleting filter succeeded in decreasing the number of adherent leukocytes during rewarming in the setting of an operation requiring the use of deep HCA. It is reasonable to assume that this reduced accumulation of leukocytes is what led to a better neurologic outcome in our previous long-term experimental model.

We express our deepest gratitude to anesthesiologist Vilho Vainionpää, $\mathrm{MD}, \mathrm{PhD}$, and biostatistician Pasi Ohtonen, MSc, for their expert guidance and assistance in this study.

\section{References}

1. Bachet J, Guilmet D. Brain protection during surgery of the aortic arch. J Card Surg. 2002;17:115-24.

2. Di Eusanio M, Di Eusanio G. Cerebral protection during surgery of the thoracic aorta: a review. Ital Heart J. 2004;5:883-91.

3. Hagl C, Khaladj N, Karck M, Kallenbach K, Leyh R, Winterhalter M, et al. Hypothermic circulatory arrest during ascending and aortic arch surgery: the theoretical impact of different cerebral perfusion techniques and other methods of cerebral protection. Eur J Cardiothorac Surg. 2003;24:371-8.
4. Chen H, Chopp M, Zhang ZG, Garcia JH. The effect of hypothermia on transient middle cerebral artery occlusion in the rat. J Cereb Blood Flow Metab. 1992;12:621-8.

5. Feuerstein GZ, Wang X, Barone FC. The role of cytokines in the neuropathology of stroke and neurotrauma. Neuroimmunomodulation. 1998;5:143-59.

6. Koskenkari J, Rimpilainen J, Biancari F, Surcel HM, Kaukoranta P, Kiviluoma K, et al. Leukocyte depleting filter attenuates myocardial injury during elective coronary artery bypass surgery. Scand Cardiovasc J. 2005;39:358-68.

7. Levine AJ, Parkes K, Rooney S, Bonser RS. Reduction of endothelial injury after hypothermic lung preservation by initial leukocytedepleted reperfusion. J Thorac Cardiovasc Surg. 2000;120:47-54.

8. Rimpilainen J, Pokela M, Kiviluoma K, et al. Leukocyte filtration improves brain protection after a prolonged period of hypothermic circulatory arrest: A study in a chronic porcine model. J Thorac Cardiovasc Surg. 2000;120:1131-41.

9. Ilmakunnas M, Pesonen EJ, Ahonen J, Ramo J, Siitonen S, Repo H. Activation of neutrophils and monocytes by a leukocyte-depleting filter used throughout cardiopulmonary bypass. $J$ Thorac Cardiovasc Surg. 2005;129:851-9.

10. Chen YF, Tsai WC, Lin CC, Lee CS, Huang CH, Pan PC, et al. Leukocyte depletion attenuates expression of neutrophil adhesion molecules during cardiopulmonary bypass in human beings. J Thorac Cardiovasc Surg. 2002;123:218-24.

11. Ilmakunnas M, Pesonen EJ, Ahonen J, Ramo J, Siitonen S, Repo H. Activation of neutrophils and monocytes by a leukocyte-depleting filter used throughout cardiopulmonary bypass. $J$ Thorac Cardiovasc Surg. 2005;129:851-9.

12. Zimmerman GA, Prescott SM, McIntyre TM. Endothelial cell interactions with granulocytes: tethering and signaling molecules. Immunol Today. 1992;13:93-100.

13. Bevilacqua MP. Endothelial-leukocyte adhesion molecules. Annu Rev Immunol. 1993;11:767-804.

14. Huber AR, Kunkel SL, Todd RF 3rd, Weiss SJ. Regulation of transendothelial neutrophil migration by endogenous interleukin-8. Science. 1991;254:99-102.

15. Muller WA, Weigl SA, Deng X, Phillips DM. PECAM-1 is required for transendothelial migration of leukocytes. J Exp Med. 1993;178: 449-60.

16. del Zoppo GJ. Microvascular responses to cerebral ischemia/inflammation. Ann N Y Acad Sci. 1997;823:132-47.

17. Tsui SS, Kirshbom PM, Davies MJ, Jacobs MT, Kern FH, Gaynor JW, et al. Thromboxane A2-receptor blockade improves cerebral protection for deep hypothermic circulatory arrest. Eur J Cardiothorac Surg. 1997;12:228-35.

18. Thurlow PJ, Doolan L, Sharp R, Sullivan M, Smith B, Andersen LW. Laboratory studies of the effect of Pall extracorporeal leucocyte filters LG6 and AV6 on patients undergoing coronary bypass grafts. Perfusion. 1996;11:29-37.

19. Scholz M, Simon A, Matheis G, Dzemali O, Henrich D, Kleine P, et al. Leukocyte filtration fails to limit functional neutrophil activity during cardiac surgery. Inflamm Res. 2002;51:363-8.

20. Anttila V, Hagino I, Zurakowski D, Lidov HG, Jonas RA. Higher bypass temperature correlates with increased white cell activation in the cerebral microcirculation. J Thorac Cardiovasc Surg. 2004;127: 1781-8. 

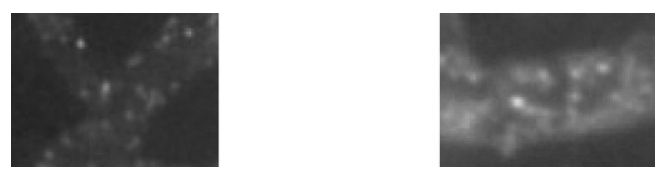

Figure E1. Left, Single leukocytes in cerebral microvasculature 60 minutes after hypothermic circulatory arrest in leukocyte filtration group animal. Right, Leukocyte accumulation in cerebral microvasculature 60 minutes after hypothermic circulatory arrest in control animal. 